\title{
TTR
}

Traduction, terminologie, re?daction

\section{Michel Ballard (dir.). Europe et traduction. Artois Presses \\ Université et Les Presses de l'Université d'Ottawa, 1998, 417 p.}

\section{Geneviève Quillard}

Volume 12, numéro 1, 1er semestre 1999

Poésie, cognition, traduction I

Poetry, Cognition, Translation I

URI : https://id.erudit.org/iderudit/037359ar

DOI : https://doi.org/10.7202/037359ar

Aller au sommaire du numéro

\section{Éditeur(s)}

Association canadienne de traductologie

ISSN

0835-8443 (imprimé)

1708-2188 (numérique)

Découvrir la revue

Citer ce compte rendu

Quillard, G. (1999). Compte rendu de [Michel Ballard (dir.). Europe et traduction. Artois Presses Université et Les Presses de l'Université d'Ottawa, 1998, 417 p.] TTR, 12(1), 191-193. https://doi.org/10.7202/037359ar d'utilisation que vous pouvez consulter en ligne.

https://apropos.erudit.org/fr/usagers/politique-dutilisation/ 


\section{COMPTES RENDUS}

\section{Michel Ballard (dir.). Europe et traduction. Artois Presses Université et Les Presses de l'Université d'Ottawa, 1998, 417 p.}

Cet ouvrage réunit trente études qui ont été présentées en mars 1966, à l'Université d'Artois, dans le cadre du colloque "Europe et traduction ", organisé par le Centre d'Études et de Recherches de l'Artois sur les Cultures et Intertextualités.

Comme le fait remarquer Michel Ballard dans la présentation de ce volume, "l'ensemble [...] tend à s'organiser en deux volets " (p. 9).

Le premier volet (les deux tiers des articles) retrace le cheminement, les pratiques, les objectifs et les effets de la traduction en Europe, de l'Antiquité romaine jusqu'à nos jours.

La traduction a longtemps eu une fonction pédagogique : elle servait à enseigner le grec et le latin qui, comme le dit Don Quichotte, étaient considérés comme " les reines des langues "; elle permettait en même temps de présenter et de tenter d'imiter, voire de surpasser, des modèles prestigieux. Cette prééminence de la culture antique, latine surtout, a duré pendant des siècles. On lit dans L'Encyclopédie, sous la plume de Diderot : " Aussi rien n'est-il plus mal imaginé à un François qui sait le Latin, que d'apprendre l'Anglois dans un dictionnaire Anglois-François, au lieu d'avoir recours à un dictionnaire AngloisLatin " (cité par Daniel Mercier, "Une "mesure commune" des langues européennes », p. 113). Au début du XIXe siècle, en France, les traductions de textes latins étaient encore nettement plus nombreuses que celles de textes anglais, allemands ou italiens.

Les traductions des textes sacrés, qui se sont multipliées avec l'expansion du christianisme, avaient elles aussi une visée didactique. Traductions et commentaires exégétiques sont alors devenus intimement liés, soit parce que les différences que présentaient les traductions incitaient à confronter les textes et à élucider leur signification, soit par désir de faire appréhender des notions 
importantes en matière de foi et d'eschatologie, comme ce fut le cas en Irlande au VIIe siècle.

La traduction a eu d'innombrables répercussions. Les traductions bibliques ont été l'agent de la standardisation du gallois et du finnois, et de l'utilisation de l'anglais en Écosse. La littérature française du règne de Louis XIII témoigne de l'influence des romans et des nouvelles espagnoles; du XVIIIe siècle jusqu'au milieu du XXe siècle, la traduction de textes scientifiques français a permis l'élaboration de la terminologie scientifique en Espagne. Les traductions de Pierre Coste ont diffusé les travaux de Locke, de Shaftesbury ou de Newton auprès de l'intelligentsia non seulement française, mais aussi allemande ou italienne. Le Faust de Goethe, traduit par Gérard de Nerval, a influencé le surnaturalisme français. La production de pièces à sujets historiques en France, au début du XIXe siècle, est liée aux traductions des romans de Walter Scott. La littérature hongroise a été influencée par la littérature française des XVIIIe et XIXe siècles. La pensée politique de Chateaubriand a marqué un certain nombre de politiciens hongrois... Bref, la traduction a permis une multiplicité d'échanges entre différentes cultures et d'influences réciproques qui ont laissé des traces indélébiles. Elle a été un puissant agent d'enrichissement linguistique et culturel et de nombreuses transformations.

Le second volet de cet ouvrage traite de questions d'actualité : formation des traducteurs, échange d'informations entre traducteurs, promotion de la qualité des traductions, notamment des traductions littéraires, harmonisation des terminologies dans les pays européens, problèmes soulevés par diverses contraintes : ainsi « tous les textes européens doivent se ressembler paragraphe par paragraphe, phrase par phrase, quand bien même l'ordre des mots, la complexité syntaxique, etc. ne sont pas identiques d'une langue à l'autre! " (Yves Gambier, "Mouvances euro-linguistiques. Cas de la Finlande », p. 297). Avec l'intégration européenne, la traduction occupe une place de plus en plus privilégiée et les traducteurs ont un rôle capital à jouer. Comme l'écrit Françoise Wuilmart : "Ce sont les traducteurs qui ont fait l'Europe [...]. Aujourd'hui, alors qu'il s'agit de bâtir une grande patrie culturelle où les identités préservées cohabiteront avec bonheur, c'est encore eux qui s'attellent à une tâche essentielle : mettre à la portée des leurs ce qui au départ leur était étranger, faire passer le message de l'Autre sans 
trop le défigurer et œuvrer ainsi dans le sens d'une tolérance et d'une compréhension mutuelle » (p. 392).

La lecture de cet ouvrage est enrichissante, non seulement pour les historiens de la traduction ou les traducteurs en général, mais pour toute personne qui s'intéresse à la diffusion et au brassage des idées, à l'ouverture à l'Autre, à la pénétration d'une ou de plusieurs cultures dans une autre. Deux choses gâchent toutefois le plaisir de la lecture de ces articles : le nombre d'erreurs typographiques (quand il ne $s$ 'agit pas de fautes d'accord!), qui est assez élevé; le fait que certains textes n'aient pas été suffisamment remaniés pour la publication et qu'ils se présentent donc comme des communications orales.

Geneviève Quillard Collège militaire royal du Canada 